\title{
StABILITY ANALYSIS QUAY WALL AT THE AMAZONEHAVEN, PORT OF ROTTERDAM
}

\author{
Nadevah K.N. Mourillon ${ }^{1}$, Jarit de Gijt ${ }^{2}$, Klaas Jan Bakker ${ }^{3}$, Henk Brassinga ${ }^{4}$, Erik Broos $^{5}$ \\ ${ }^{1}$ Structural Engineer, Hydraulic \& Civil Engineering dept., Municipality of Rotterdam, The \\ Netherlands. ${ }^{2}$ Ass. Professor Hydraulic Engineering Dept., University of Delft, Senior consultant, \\ Engineering Dept., Municipality of Rotterdam, The Netherlands. ${ }^{3}$ WAD 43 bv Consulting Engineers, \\ The Netherlands. ${ }^{4}$ Geotechnical consultant, Delft, The Netherlands. ${ }^{5}$ Port of Rotterdam, The \\ Netherlands.
}

\begin{abstract}
The stability of any structure is an important aspect in civil engineering. This aspect is the subject of the researched quay wall at the Amazonehaven, port of Rotterdam. The quay wall with a relieving platform structure had in various section, over the entire $900 \mathrm{~m}$ length of the quay, large deformations at the toe of the combined wall. The purpose was to analyse and quantify the influence of the deformed combined wall on the stability of the quay wall, its service lifetime. To obtain a better insight into the concept of stability, analytical methods based on the Blum theory, beam on elastic foundation method and finite element method using Plaxis 3D were applied and compared. The finite element method, Plaxis 3D, proved to be a better method to investigate the quay wall. Plaxis 3D takes into account the 3-dimensional effects of the quay wall and considers the actual soil behaviour during calculation which is a sophisticated manner of modelling a quay wall. A calibration model (which is the actual designed quay wall) and a series of models with various penetration depth of the combined wall are modelled. Also, a safety analysis of the soil parameters were applied to the various models.
\end{abstract}

\section{Introduction}

In the 1980's, it was of great importance to the port of Rotterdam, while competing with other major loading ports in countries such as Australia, the United States of America, Canada, South America and South Africa, to be able to facilitate vessels greater than 100000 dwt. With this in mind, the E.M.O. deep-sea terminal (Fig. 1) was constructed for the throughput of iron and coal which was realized in 1990. This $900 \mathrm{~m}$ long deep-sea quay terminal is located at the Maasvlakte I at the Amazonehaven. In Fig. 1 the cross section of the quay wall is illustrated. 


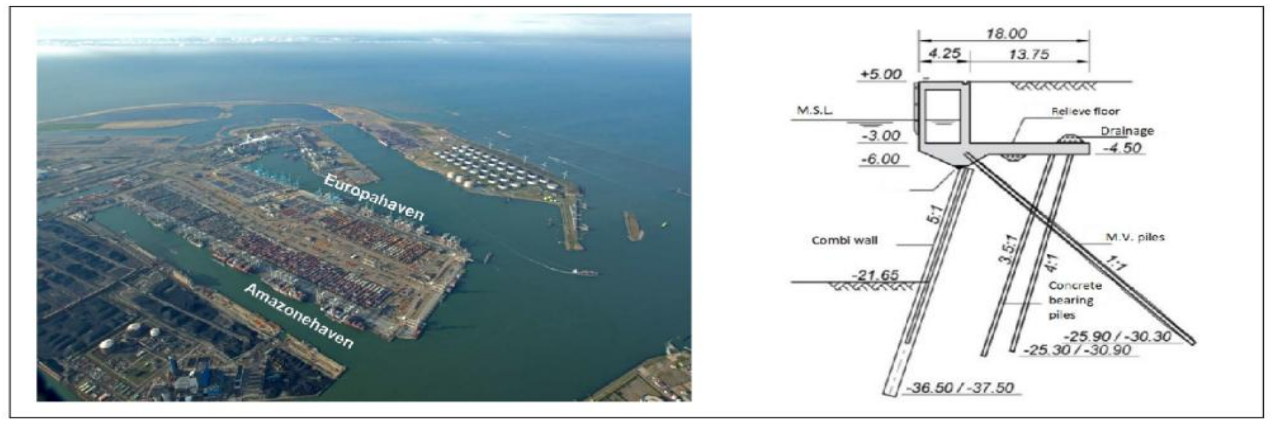

Fig. 1 Overview of the 'Europees Massagoed Overslagbedrijf' (E.M.O.) at the Amazonehaven (Left); Cross section of the quay wall at the Amazonehaven [10] (Right)

The widening at the south side of the Amazonehaven harbour basin must be realized due to the rapid growing of the container vessels mooring in the Amazonehaven. During the demolition of the old quay wall much damage are discovered at the tip of the open tubular and intermediate sheet piles. This was an unexpected discovery which according to the recorded events that took place during its service lifetime was not known. The damages to the open tubular piles consist of folding of the pile toe, completely closed pile toe, ovalisation at the pile toe or other damages. In Fig. 2 typical damages to the tubular piles are illustrated.

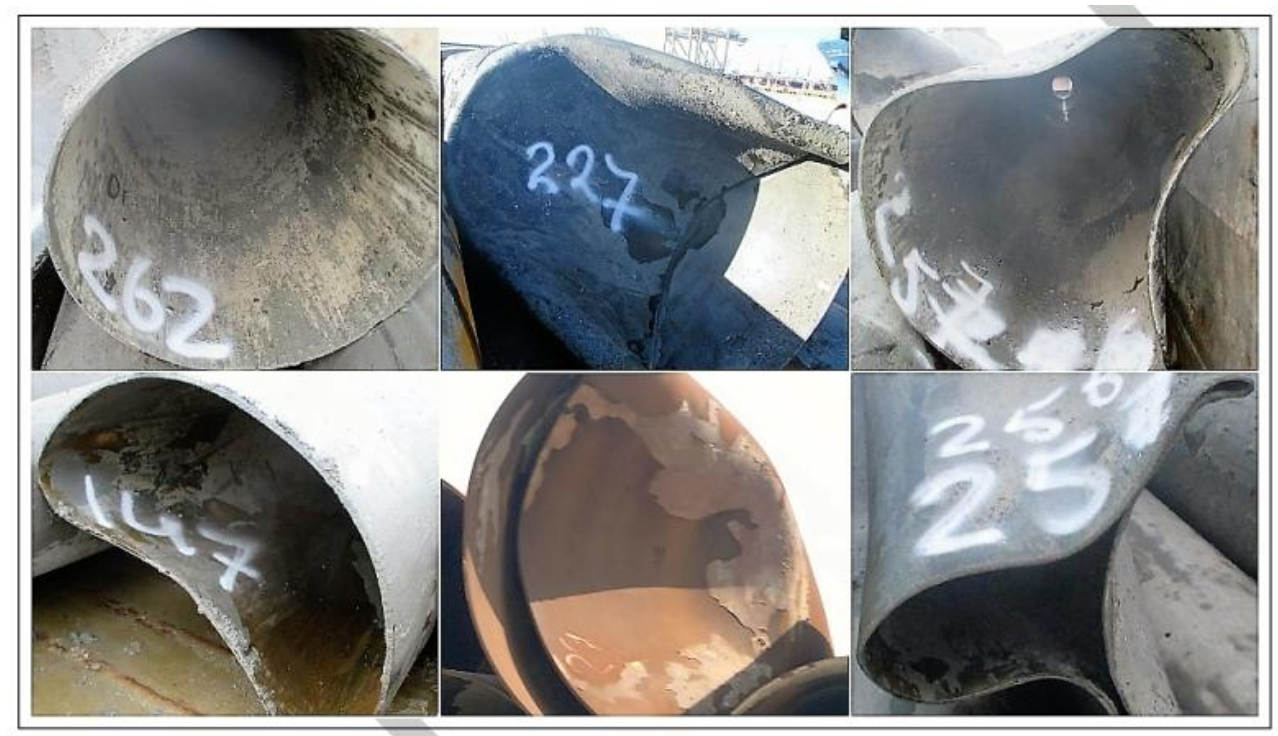

Fig. 2 Various types of damages to the tubular piles [10]

A rough estimation of the damages to the open tubular piles is to about $15 \%$ to $20 \%$ of the piles. In the case of the intermediate sheet piles roughly $50 \%$ seems to be damaged. All the damages are at the toe of the sheet pile because of the interlock openings that occurred during construction. These unexpected damages lead to the investigation of the structural stability mechanisms of the deep-sea quay wall. In this paper the stability of the quay wall at the Amazonehaven for its service lifetime will be discussed. 


\section{Methods}

Various design calculation methods are available for the design of a quay wall. These methods are:

\subsection{Blum method - Classic (analytical) method}

This design calculation method is used to determine the strength of the combined wall of the quay wall. The results of the analytical calculations with Blum, no specific answers were found on the stability of the quay wall. The reason for this is that with this method based on the load distribution only the penetration depth can be determined. The corresponding moment and shear force can also be derived. However, the actual earth pressure redistribution caused by arching of the soil behind the combined wall is not taken into account in this method. Furthermore the various construction stages are not taken into account in this analytical method.

\subsection{D-Sheet Piling - Beam on elastic foundation method}

The calculation method for beam on elastic foundation (D-Sheet Piling) is more complex than the previous method. The calculations with D-sheet piling software are restricted to determining sheet pile dimensions. The interface relation between soil and structural elements will be assumed linear in the elastic area and the springs. The behaviour of the soil is represented both horizontally and vertically and mutually uncoupled.

The inclined combined wall for the quay wall is considered vertical when modelling in Dsheet piling software. The inclination effects of the combined wall which are favourable, are not considered. The eccentricity of the axial load reduces the maximum bending moment, meanwhile second order moment effects will be unfavourable to the stability of the combined wall. That is why, the second order effects will not be taken into account.

\subsection{Plaxis -Finite Element Method}

In favour to previous methods, the finite element method (Plaxis 3D) is based on a model in which the soil behaviour and the contained construction elements are integrated. This method is done based on the stress equilibrium and deformation of soil and bending behaviour of the construction elements are described by a linked system consisting of partial and ordinary differential equations.

The advantage of this method is the displacement of the soil directly around objects, in this case the soil against the combined wall can be calculated. For that reason, this method should be applied in case that objects nearby are sensitive to the deformations of the soil during the construction of the wall. The effect of the construction on the object can then be calculated. This method is also applied for three-dimensional problems when the distribution of the earth pressures over the primary members and intermediate piles in a combined wall have to be taken into account.

\section{Results and Discussion}

A static analysis under the serviceability loading conditions has been preliminary performed. The relationship of the stability of the quay wall is determined by using Blum method, DSheet Piling and Plaxis 3D. 


\subsection{Modelling}

For the design of the quay wall three methods were used. The first two methods, Blum and D-sheet Pilling, were the least reliable for determining the stability of the quay wall. With these methods an estimation is obtained of the penetration depth, bending moment, shear forces and displacement.

The quay wall is the input model in Plaxis 3D. This allows for a more accurate quay wall modelling, specifically oblique installed combined walls and the analysis and evaluation of plastic deformation are also possible. In order to understand the deformation behaviour of the quay wall, specifically the combined wall, a calibration model (Fig. 3) is set up. This model is based on the original designed quay wall without surface loads. This model can be compared to the results from the other five models (Fig. 4, 5 and 6) based on the deformation of the foundation elements and relieving platform structure. The reason for this is the stability of the quay wall model is not only dependent on the deformation of the combined wall but also on the displacement of the foundation elements and relieving platform structure as well.

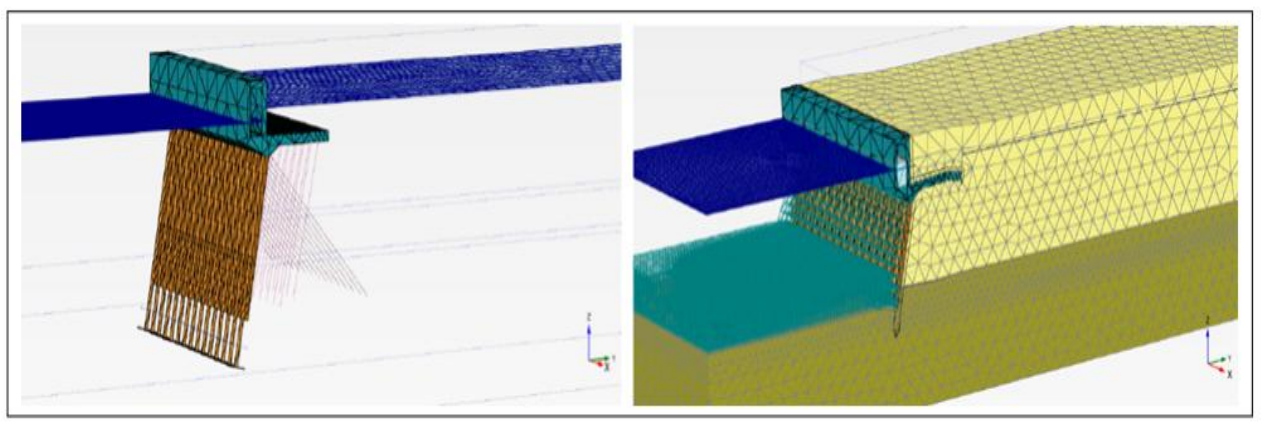

Fig. 3 Deformed mesh of the calibration model (Left) and schematization quay wall model (Right) [1]

\subsection{Five quay wall model simulations}

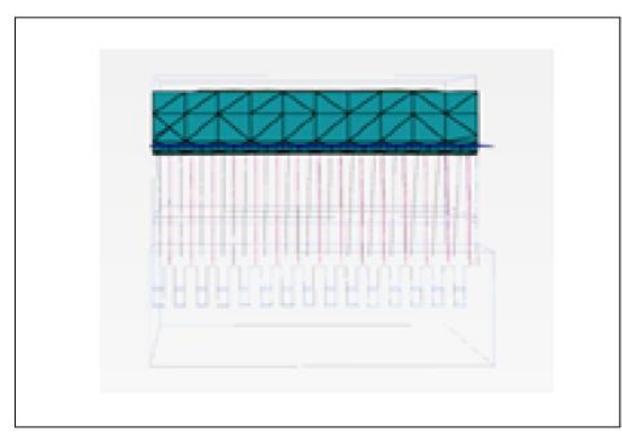

Fig. 4 Quay wall without combined wall 


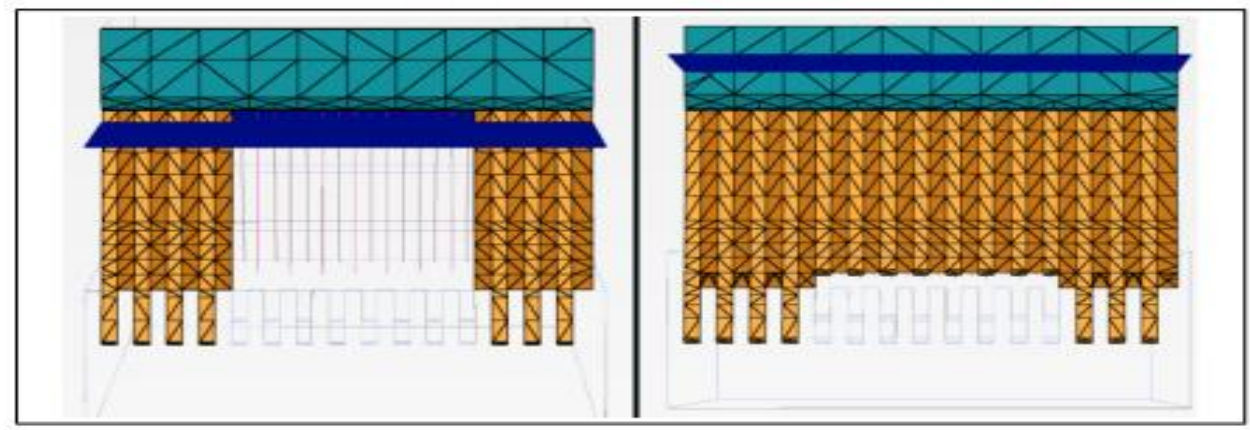

Fig. 5 Quay wall simulated on two supported ends - Model 2A (Left) and Model 2B (Right)

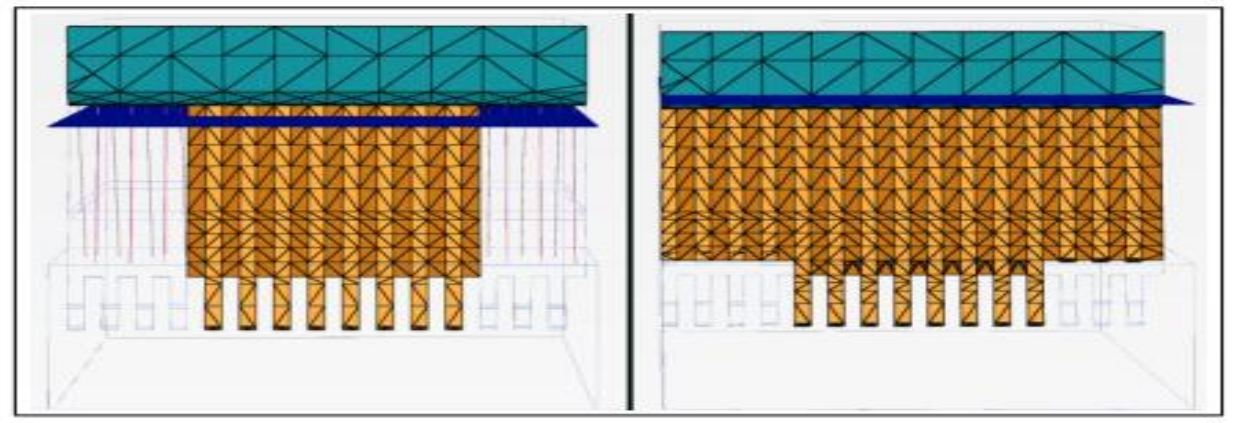

Fig. 6 Quay wall simulated on one supported end - Model 3A (Left) and Model 3B (Right)

From the results, comparison between the various quay wall models and the calibration model can be concluded that Model 2B and calibration model can be further investigated.

\section{Results and discussion}

In this section, the results from D-sheet and Plaxis 3D are presented. In the Fig. 7 below the results from D-Sheet is analysed for both combined wall models (Uniformed and trapezium distributed surcharges). The relation between the minimum penetration depth and bending moment are presented with different surcharges $(0,200$ and $450 \mathrm{kPa})$ with a construction depth of NAP-25,50m. 

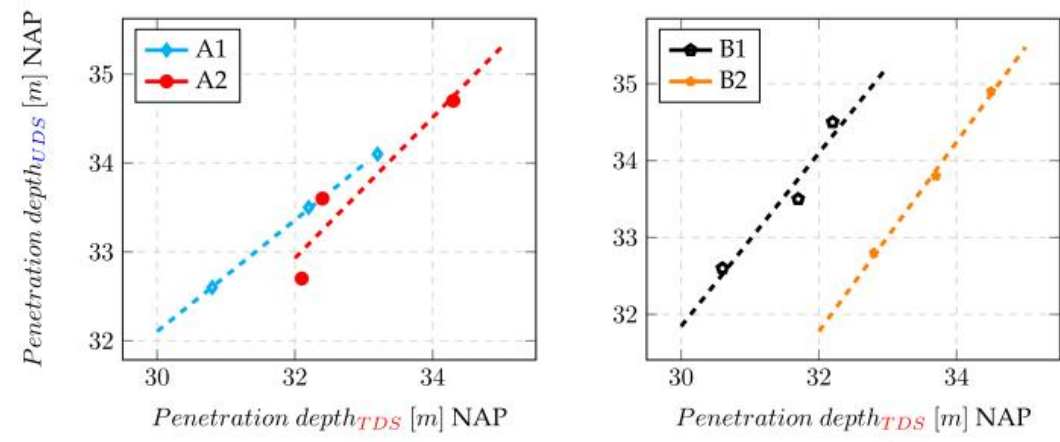

Fig. 7 The relation between the minimum penetration depths for a Trapezium Distributed Surcharges (TDS) and Uniformed Distributed Surcharges (UDS) for various load cases [1]
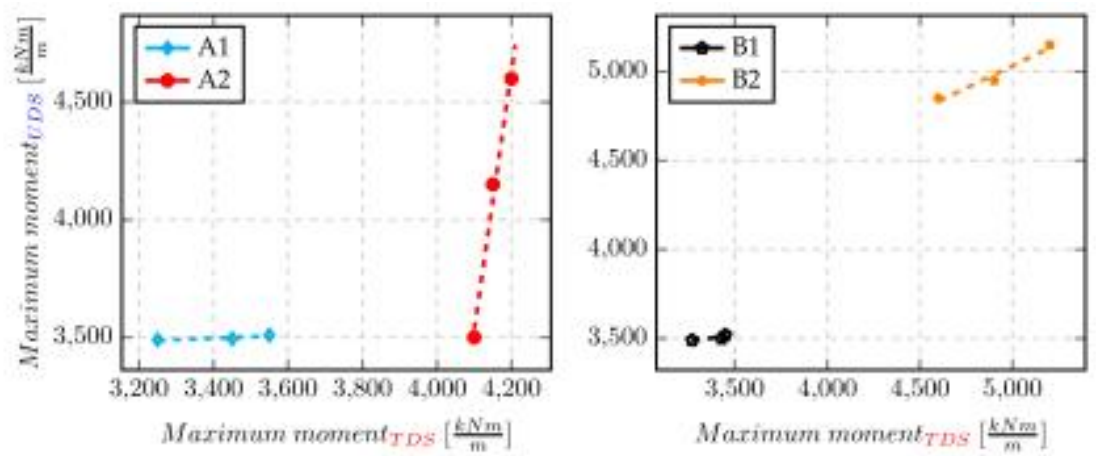

Fig. 8 The relation between the minimum penetration depths for a Trapezium Distributed Surcharges (TDS) and Uniformed Distributed Surcharges (UDS) for various load cases [1]

From the comparison between the two models it can be concluded that by modelling the distribution of the surface loads as a trapezium or uniformly the difference of minimum penetrated depth of the combined wall is considerably small. Furthermore, the field bending moment increases as the surface load increases which leads to a freely imposed bending moment. When the combined wall is shorter than the calculated minimum penetrated depth the quay wall model becomes unstable. With a 2-dimensional software such as D-sheet piling it is apparent that the (in) stability of the quay wall is not investigated for the entire length of a quay section of 45 meters. It is only a cross section per meter that is calculated.

Therefore, to implement the 3-dimensional effects, a 3-dimensional method would be very helpful in analysing the actual stability of the entire quay wall. The three dimensional finite element models of the quay wall is presented. 


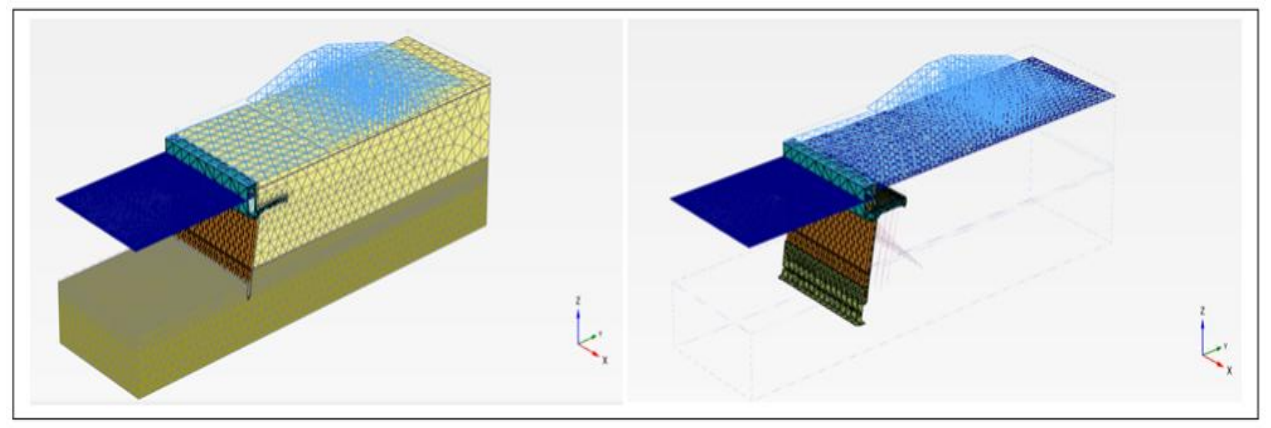

Fig. 9 Deformed mesh calibration model with designed surcharge (Left) and deformed mesh calibration model with designed surcharge without soil (Right)

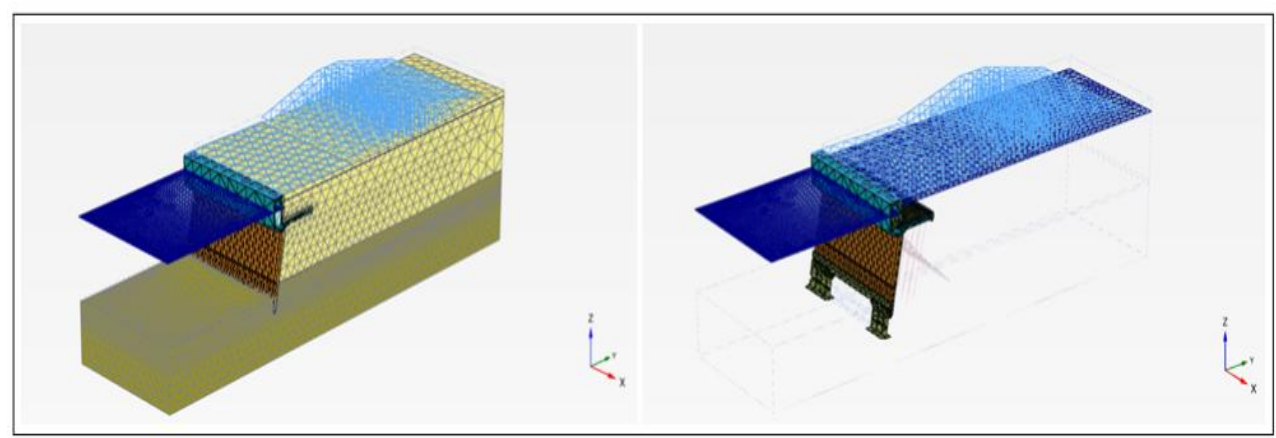

Fig. 10 Deformed mesh model 2B with designed surcharge (Left) and deformed mesh model 2B with designed surcharge without soil (Right)

The results of the previous models of the quay wall are compared to the calibration model and model 2B based on the structural stability.

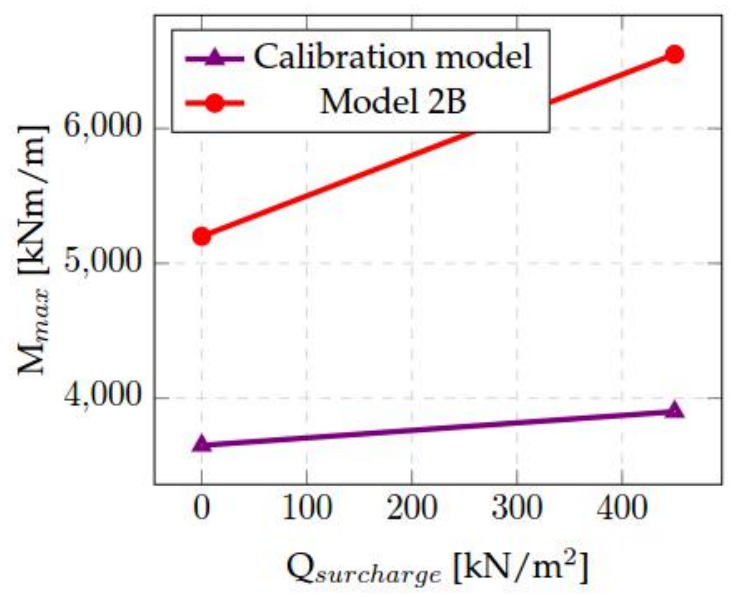

Fig. 11 Comparison maximum moment between calibration model and model 2B

In Fig. 10 a comparison between the two models is illustrated. As it can be observed from the graph the maximum bending moments in model $2 \mathrm{~B}$ are higher than in the calibration 
model. The reason for this is that model $2 \mathrm{~B}$ has an opening at the centre of the combined wall. Because of this opening the redistribution of the moment will be higher at the sides than the centre of the combined wall where the opening is situated.

Table 1 Safety comparison between calibration model and model 2B

\begin{tabular}{|c|c|c|}
\hline & $\begin{array}{c}\text { Calibration model } \\
\text { with surcharge }\end{array}$ & $\begin{array}{c}\text { Model 2B } \\
\text { with surcharge }\end{array}$ \\
\hline Unity Check & 0.738 & 1.436 \\
\hline Safety margin & 1.355 & 0.696 \\
\hline Safety factor & 1.494 & 1.473 \\
\hline
\end{tabular}

The safety analysis results in a safety factor which can be obtained by reducing the strength parameters incrementally. Starting from un-factored values that are inputted when creating the soil layers of the models $\phi_{\text {avail }}$ and $c_{\text {avail, }}$, until equilibrium can no longer be achieved in the calculations $[7,8,9]$. The results represents the behaviour of the loads acting on the quay wall, in this case the self-weight, at the defined construction phase. The safety factor value (S.F.-value) for the calibration model is equal to $\mathbf{1 . 4 9 4}$ and for model $2 \mathrm{~B}$ this is $\mathbf{1 . 4 7 3}$. The safety factor value implies the reduction factor that is imposed on the friction angle and cohesion until the quay wall becomes unstable.

Apart from the S.F.-value a unity check and safety margin of these two models were determined which can be expressed in a mathematical equation:

$$
\begin{aligned}
& \sigma=\frac{N}{A}+\frac{M}{W} \leq \sigma_{\text {yield }} \\
& \frac{\sigma}{\sigma_{\text {yield }}}<\text { F.S.Value }
\end{aligned}
$$

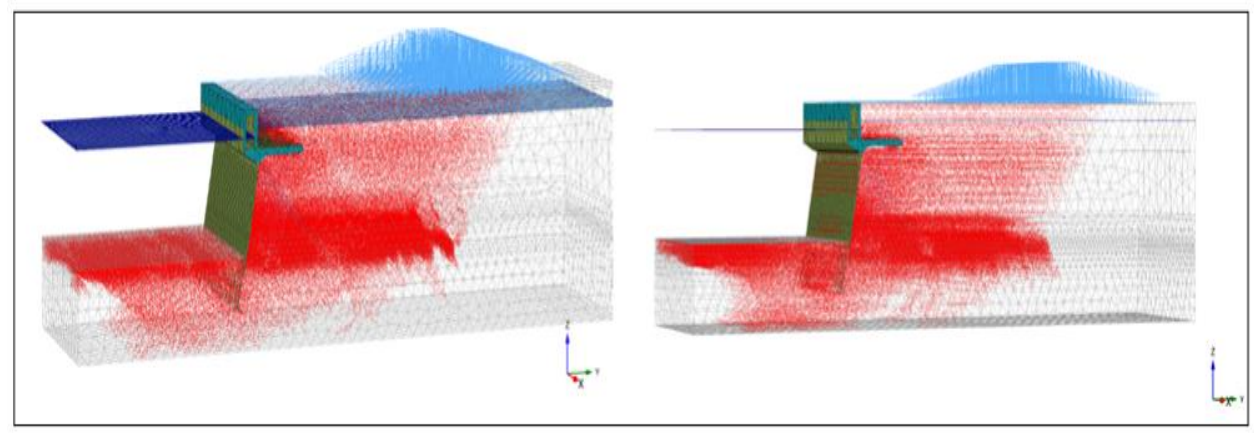

Fig. 12 Plastic points calibration model (Left) and plastic points model 2B (Right) 


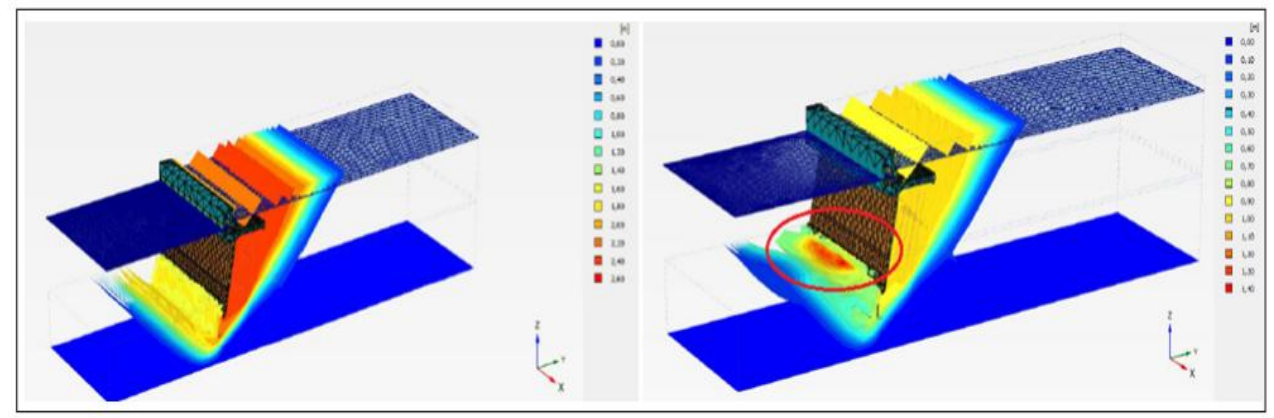

Fig. 13 Phase displacement calibration model (Left) and phase displacement model 2B (Right)

In Fig. 11 a comparison is shown for both model which shows that underneath the combined wall higher stresses occur and these are very interesting to analyse. This figure shows for both model the potential of numerical methods when investigating failure mechanisms soilstructure interaction should be taken into account. The structural elements, specifically the combined wall, will yield due to the effective horizontal soil pressure from the active side. The effective horizontal soil pressure on the active side underneath the relieving platform structure, which can be recognized by the red points, becomes larger than the effective horizontal soil pressure on the passive side.

However, the phase displacements of the models (Fig. 12) a difference can be observed at the passive side. The contour lines are different at the passive side in front of the combined wall. In Fig. 12 at the passive side the phase displacement is larger and at the surface level of the harbour basin. This is because of the opening being two meters below the construction depth, N.A.P. $-25.50 \mathrm{~m}$. According to the $\varphi / \mathrm{c}-$ reduction calculation for Model $2 \mathrm{~B}$ and the calibration model the calculated deformations are not realistic, but it can illustrate how the quay wall model will behave.

\section{Conclusions and Recommendations}

- The actual quay wall shows no instability.

- In Plaxis 3D, Model 2B will become unstable when exposed to unfavourable conditions. The deformation behaviour of the combined wall will be too large due to higher loads than anticipated. However, the safety factor value of model 2B comes close to the safety coefficient of 1.5 which was used on the quay wall during the design process. Therefore, it can be concluded that even though the quay wall was never fully loaded it was strong enough to retain the loads it was exposed to during its service lifetime. Also the superstructure was strong enough and capable to retain all the excess loads without collapsing although the combined walls never reached its designed penetration depth.

- The results shows how the quay wall behaved during its service lifetime. And it also illustrates both models will fail due to steel yielding and subsequently failure of the passive soil resistance.

- The influence of the interaction between deep and hard soil layers and open tubular piles during pile driving should be investigated. 


\section{References}

1. N.K.N. Mourillon, J.G. de Gijt, K.J. Bakker, T. Vellinga, P. Taneja, S.H.J. van Es, E.J. Broos, Stability analysis quay structure at the Amazonehaven port of Rotterdam (2015)

2. J.G. de Gijt, M.L. Broeken, Quay walls, Second edition SBRCURnet Publication $211 E(2014)$

3. J.G. de Gijt, A.A. Roubos, D. Grotegoed, SBRCUR 186 Binnenstedelijke kademuren. (2014)

4. J. Grabe, Sheet piling handbook design (2008)

5. CUR Bouw \& Infra, Damwandconstructies. SBRCURnet Publication CUR 166 (2012)

6. C.N. van Schaik, J.G. de Gijt, Diepwater terminal Amazonehaven zuidzijde (1989)

7. Plaxis, Reference Manual (2013)

8. Plaxis, Material Models Manual (2013)

9. R.B.J. Brinkgreve, H.L. Bakker, Non-linear finite element method analysis of safety factors. In Proc. $7^{\text {th }}$ Int. Conf. on Comp. Methods and Advances in Geomechanics. Cairns, Australia (1991)

10. R. Nejad, J.G. de Gijt, J. Verlaan, H. Pacejka, P. Middendorp, S.H.J. van Es, Research into pile toe failure in Amazonehaven (to be published) 